\title{
Studying the influence of the cross section height on the distribution of the internal efforts of wooden glued beams
}

\author{
Sergei Prokhorov ${ }^{1^{*}}$ \\ ${ }^{1}$ Vladimir State University named after A. and G. Stoletovs, Gorkiy street, 87, Vladimir, 600000, \\ Russia
}

\begin{abstract}
Since ancient times, wooden structures have been used by man for the construction of buildings and facilities. For many centuries, the structural elements of buildings and facilities made of wood have been the main ones, and still have broad prospects for use in modern capital construction, as they have sufficient high strength and stiffness, are reliable and durable, while having a small mounting weight. In particular, a number of Western countries are already erecting high-rise buildings using a framework of laminated wood constructions. The indisputable advantage of wooden structures is environmental friendliness. However, with all the harmony of the wood structure, its tracheid's are not standard, which is the main reason for the variability of its mechanical properties. With alteration of a cross-section of flexural member, the nature of the load distribution, as well as the nature of the fracture, changes. An additional factor that affecting the force distribution is the nature of the reinforcement and methods of the reinforcement fixing methods. The methods used to calculate the "low" reinforced beams often give a large error in the calculation of "high" beams. In the work, a rational methodology for calculating wooden glued reinforced beams with symmetrical reinforcement is determined.
\end{abstract}

\section{Introduction}

Wooden structures have been used in the construction of buildings and facilities for many centuries. Along with the indisputable positive qualities of wood, such as low deadweight with relatively high strength and stiffness, there are also negative ones - the dependence of properties on its structure, the presence of defects, massive sections, etc. In addition to this, being an organic material, wood has a cellular structure. In their structure, the cells are not uniform in size and location, and as a result, the resistance of wood to destruction in various directions is dramatically different. This property of wood is called orthotropy. [1,2]

To increase the efficient use of wooden structures, glulam is used. In comparison with traditional material, it has greater strength, resistance to aggressive environments, fire

\footnotetext{
*Corresponding author: oc204@bk.ru
} 
resistance, etc. In addition, in order to increase the bearing capacity and to reduce the cross section of the bent elements, reinforcement with steel or composite rods is used. [3,4]

When selecting the cross section of reinforcement, to strengthen wooden structures, it is necessary to take into account not only its strength, but also elastic characteristics, since the ratio of normal stresses in reinforcement and wood during their normal joint operation depends on the ratio of their elastic modulus. [5]

In addition to this, an important point is the design of structures, taking into account the full use of the physicomechanical and operational properties of wood and reinforcing material. [6.7]

The issue of the influence of the cross-sectional dimensions of bent elements of wood and composite materials on bending resistance has been studied by many authors. $[8,9,10]$ In the process of analysis, it was found that with an increase in the section height, the flexural strength of glued structures decreases, and the degree of reduction does not have a linear dependence. [11] The mathematical model and calculation methods used for beams with a ratio of $\mathrm{h} / \mathrm{l}=1 / 20$ have significant differences in-place tests of beams with a ratio of $\mathrm{h} / \mathrm{l}=1 / 10-1 / 12$.

In addition, the researchers noted that with an increase in the cross-sectional height of the structures, a reduction in shearing resistance occurs and the nature of the fracture behavior. Most of these phenomena are expressed in the by-support area. [12,13]

The analysis of the works shows that the testing of standard samples does not provide an adequate picture of the nature of the distribution of forces in the body of the structure. Full-scale testing of elements has a high cost and complexity, which entails a rise in design cost.

In the studied works, the determination of the value of the temporary shear resistance was carried out using the formula corresponding to the parabolic law of the stress distribution. Which, as practice has shown, did not reflect the actual nature of the destruction and distribution of shear stresses, over the body of the structure, for a number of constructions. In addition, wood was crushed in the compressed zone of the reinforced structures. A number of studies did not take into account the effect of section sizes at the microstructure level with congenital macro defects of structures.

In view of the above, there arises a question of studying changes in internal stresses in the body of glued wooden reinforced beams, by non-destructive methods. At the moment, various software systems are used to study the stress-strain state of structures, which allow us to assess the effect of reinforcement on internal stresses and the nature of failure. $[14,15,16]$

\section{Materials and methods}

For research there was adopted a wooden glued reinforced beam of rectangular cross section with symmetrical reinforcement.

The main material of the beam is pine of the second grade, class $\mathrm{k} 24$.

Characteristics of the main material:

- characteristic strength of wood to bending along the fibers $-\mathrm{Ra}=240 \mathrm{~kg} / \mathrm{cm} 2$;

- characteristic strength of wood to to tensile along fibers $-\mathrm{Rt}=150 \mathrm{~kg} / \mathrm{cm} 2$;

- characteristic strength of wood to compression along the fibers - Rc $=230 \mathrm{~kg} / \mathrm{cm} 2$;

- characteristic strength of wood to chipping Rcc $=32 \mathrm{~kg} / \mathrm{cm} 2$;

- modulus of elasticity of wood along the fibers - EM=100000 kg / cm2;

- modulus of elasticity of wood across the fibers - EM90 $=4000 \mathrm{~kg} / \mathrm{cm} 2$;

- Poisson's ratio of wood along the fibers, with stresses directed across the fibers $-v 0.90$ $=0,018$.

Reinforcing steel: 
- breaking point - Rsn $=4000 \mathrm{~kg} / \mathrm{cm} 2(390 \mathrm{MPa})$;

- design strength $-\mathrm{Ra}=3750 \mathrm{~kg} / \mathrm{cm} 2$;

- elastic modulus - $\mathrm{Ea}=2100000 \mathrm{~kg} / \mathrm{cm} 2$;

The calculation model is a flat element reinforced with rod elements. The calculation is based on the fact that the deformation moduli along and across the fibers are not equal (orthotropy). Thus, the wood of the constructions, when working in tension and compression, has different deformation moduli along and across the fibers, the materials of the complex constructions work within elastic deformations compliance with the hypothesis of flat sections, the deformation of reinforcement and wood are equal.

This calculation method most fully reflects the actual nature of the construction work under load.

Two variants of the structural cross-section were chosen for the study: the "high" beam 100x1815 and the "low" 200x924. The span of all beams was 18 meters.

For calculations, the following characteristics of materials were adopted:

For wood:

- modulus of elasticity along the fibers $\mathrm{E} 1=100000 \mathrm{~kg} / \mathrm{cm} 2$;

- Poisson's ratio along the fibers $-v 0.90=0,018$;

- the modulus of elasticity across the fibers E1 $=4077.4 \mathrm{~kg} / \mathrm{cm} 2$;

- Poisson's ratio across the fibers $-v 90 . .0=0,45$;

- modulus of shearing - $\mathrm{G}=5000 \mathrm{~kg} / \mathrm{cm} 2$;

- specific gravity of the material R0 $=500 \mathrm{~kg} / \mathrm{cm} 3$;

Fittings were accepted in accordance with the gage "Hot-rolled steel round. Shortened gage"

Profile $40 \mathrm{~mm}$. Reinforcement percentage $\mu=3 \%$. The load is applied to the nodes, with a step of $0.2 \mathrm{~m}$ at each point, which corresponds to a uniformly distributed load. In a similar way, it is possible to track the stress-strain state of the beam during step by step loading.

Beam reinforcement is shown in Fig.1.

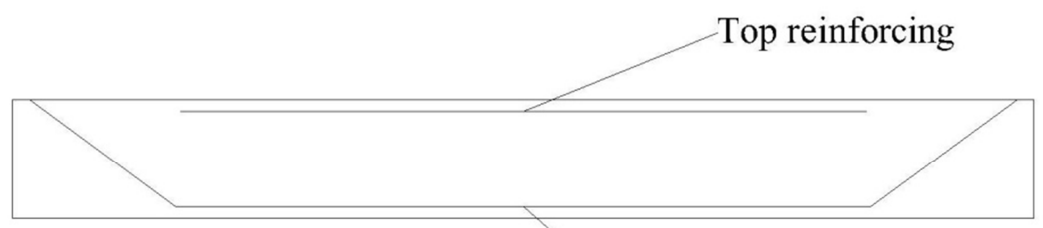

\section{Lower reinforcing}

Fig. 1. Reinforcement of laminated wood beam.

The design diagram of the beam is a beam on two beam seats loaded with a uniformly distributed load. (Fig. 2)

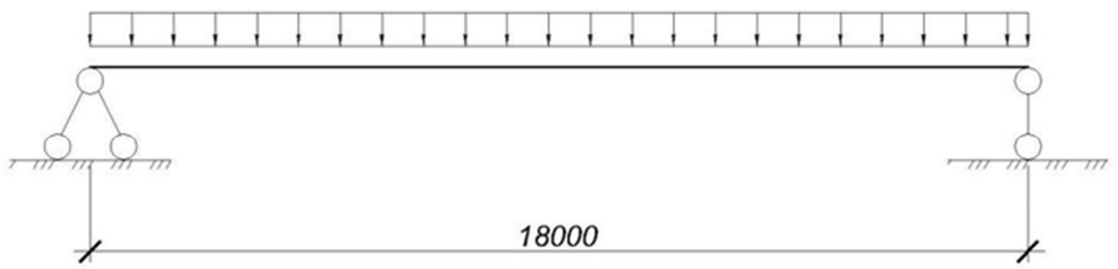

Fig. 2. Beam designdiagram.

Options of the structures cross-sectional are presented in Fig. 3. 
a)

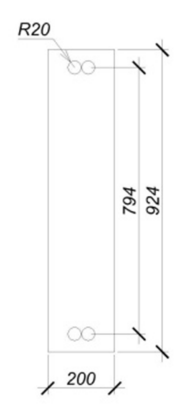

b)

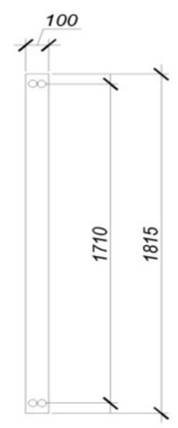

Fig. 3. The cross section of the beams according to the options: a- "low" beams; b - cross section of a "high" beam.

At the initial stage, finite elements for solving linear problems were used to simplify calculations and determine the rational method of reinforcement. Universal rectangular finite elements of the plane problem of elasticity theory (beam-wall) FE23, FE24 were used to calculate the beam taking into account orthotropy. The universal rod FE 10 was used to set the reinforcement.

After specifying the optimal arrangement of the reinforcement in the body of the structure and the nature of the reinforcement, finite elements were used for physically nonlinear problems. In particular, the body of the beam consisted of rectangular elements, the beam-wall FE 221, and in areas pairing with reinforcement FE 222. The dimensions of the elements were determined based on the computing power of the computer and the required accuracy of calculations. The calculation of the loading of the structure was carried out on the basis of the step method.

To simulate the rebar used universal spatial rod finite elements FE 205.

The load is applied to the nodes, at each point with a step of $0.2 \mathrm{~m}$, which corresponds to a uniformly distributed load. Thus, it is possible to track the stress-strain state of the beam during step-by-step loading.

Since according to the calculation requirements of the PP. 7.14-7.15 SP 64.13330.2017, the flexibility of the compressed zone from the plane greater than 300 , to ensure the sustainability of beams of plane bending was introduced connection on the upper belt with a step of 1.5 meters. The type of ties was adopted hinged in the longitudinal direction and rigid in the transverse direction of the span of the beams. The design scheme is shown in fig. 4

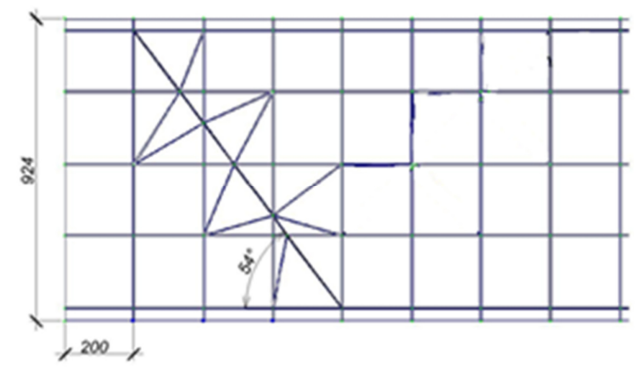

Fig. 4 Calculation model of the beam in the Lira program. 


\section{Results}

As practice shows, for beams with a relative height of $1 / 25-1 / 22$ of the span having the scheme of destruction of normal section calculation of the cross section are given without taking into account the compliance of the connection fittings-wood underestimates the theoretical results to an average of $30 \%$, and for beams with a relative height of $1 / 18-1 / 10$, collapsing in primarnoj area, exceeding the theoretical breaking point of the experimental reaches $74 \%$. Therefore, the calculation was made on the full cross section, taking into account the flexibility of the adhesive joint steel-wood.

The engineering calculation was based on the following assumptions and assumptions: all materials of complex construction, including glue, follow Hooke's law; Poisson's ratio of reinforcing bars is zero; bending stiffness of reinforcing bars is not taken into account; reinforcing bars are strictly placed on the axes of the channels; in the main material-wood is not violated the law of flat sections, except for the zones surrounding the reinforcing bars

The main results with experimental data required for an analytical comparison are given in table 1. In addition, there was performed a calculation according to SP 64.13330.2011 "Wooden structures".

Table 1. Calculation data for "low" beams with various reinforcement options.

\begin{tabular}{|c|c|c|c|c|c|c|}
\hline \multirow[t]{3}{*}{ Indicators } & \multicolumn{2}{|c|}{ Option 1} & $\begin{array}{c}\text { Enginee } \\
\text { ring } \\
\text { calculati } \\
\text { on } \\
\text { accordin } \\
\text { g to SP } \\
64.1333 \\
0.2011\end{array}$ & \multicolumn{2}{|c|}{ Option 2} & 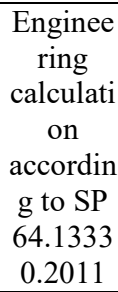 \\
\hline & \multicolumn{6}{|c|}{ Load q, $\mathrm{kg} / \mathrm{m}$} \\
\hline & 2750 & 3000 & 2438 & 5000 & 5250 & 4563 \\
\hline $\begin{array}{l}\text { Compressive } \\
\text { strength in } \\
\text { wood } \sigma q . w . c, \\
\mathrm{MPa}\end{array}$ & -19.8 & -20.8 & 21,5 & -16.2 & -17.1 & -18 \\
\hline $\begin{array}{c}\text { Stretching } \\
\text { strength in } \\
\text { wood } \sigma \mathrm{q} . w . s, \\
\mathrm{MPa}\end{array}$ & 19.5 & 20.5 & 21,5 & 14.09 & 14.77 & 18 \\
\hline $\begin{array}{c}\text { Compressive } \\
\text { strength in } \\
\text { wood } \sigma a . c ., \\
\mathrm{MPa}\end{array}$ & -389.29 & -409.12 & -390 & -242.17 & -253.96 & -212 \\
\hline $\begin{array}{c}\text { Stretching } \\
\text { strength in } \\
\text { wood oa.s, } \\
\mathrm{MPa}\end{array}$ & 389.21 & 409.08 & 390 & 248.13 & 260.19 & 212 \\
\hline $\begin{array}{c}\text { Tangents } \tau \mathrm{xz} \\
\mathrm{MPa}\end{array}$ & 2.9 & 3.05 & 1,87 & 3.12 & 3.27 & 3,2 \\
\hline $\begin{array}{l}\text { Deflection } \mathrm{f}, \\
\mathrm{mm}\end{array}$ & 45 & 52 & 37 & 50 & 52 & 45 \\
\hline
\end{tabular}

Studies have shown the influence of the scale effect on the design characteristics of the bent glued wooden elements. So the distribution of forces in the" low "reinforced beams is completely different than in the "high". Limit load determined based on the SP 64.13330.2011 full cross-section was significantly less than in the result of software 
calculations and field tests. At the same time, the nature of destruction changes: in the "low" beams, the first limit state is reached by reinforcement from the action of normal forces, and in the "high" wood from the action of shear stresses.

The distibution of forces in the beams according to the options shown in Fig.5.

a
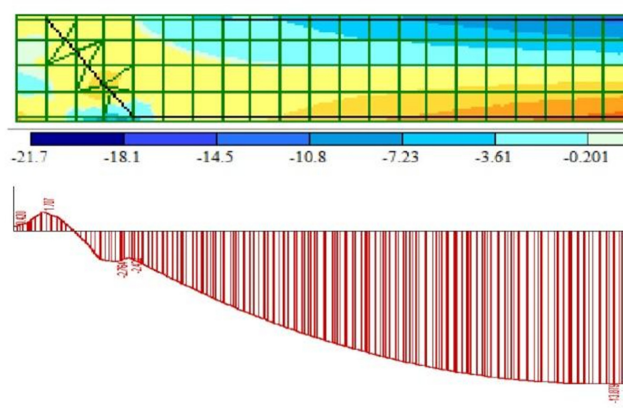

$\mathrm{c}$
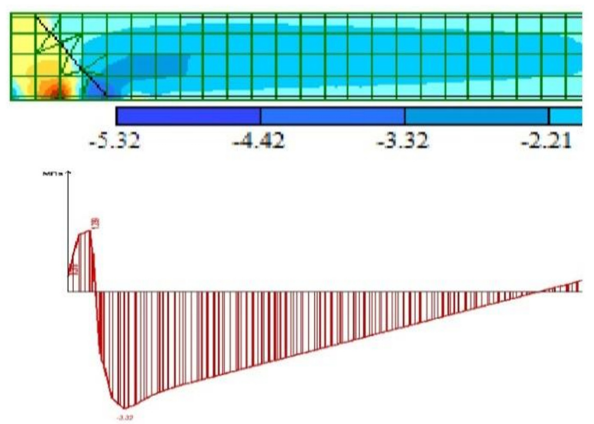

b

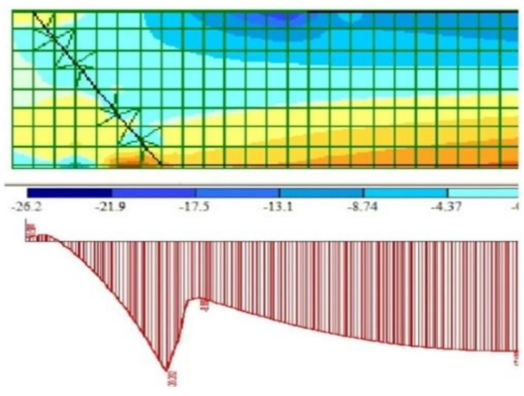

d
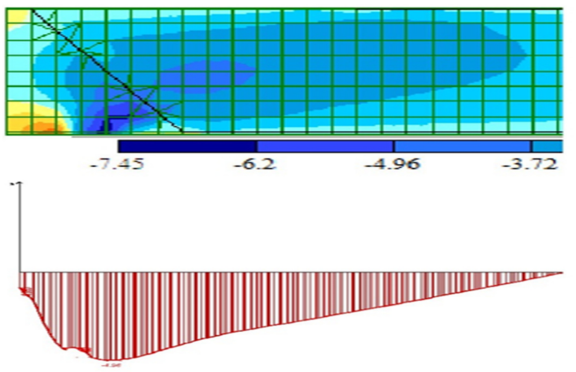

Fig.5. Distribution of normal and tangential stresses in beams according to the options: a- normal stresses arising in a "low" beam; b - normal stresses arising in the "high" beam; c - shear stresses arising in the "low" beam; $\mathrm{d}$ - shear stresses arising in the "low" beam.

\section{Discussions}

Taking into account the ultimate deformation of wood fibers and reinforcement, it can be concluded that the stresses in the reinforcement reach the yield strength before the strength of the wood is exhausted. At the same time, the reinforcement prevents brittle structural failure due to the fact that it partially retains its bearing capacity outside the yield site, demonstrating the effect of spring pull or sprengel.

The analysis shows that the calculation method given in SP 64.13330.2011, developed on the basis of an idealized diagram of the work of wood can be used only for low beams, collapsing along the normal cross-section, and gives good convergence of experimental values with theoretical values in a narrow range.

When analyzing the results, the following features should be noted:

1. The destruction of the "low" beams occurs in the middle of the span because of reaching the ultimate normal stresses in the reinforcement. Meanwhile, the tensile forces in the wood in the stretched zone reach their critical values much earlier, which causes the 
installation of reinforcement in the stretched zone. "High" beams are destroyed in the support zone once reaching ultimate tangential stresses.

2. The nature of the distribution of tangential stresses in the support zone of "high" beams is more pronounced in comparison with "low" ones, which leads to the formation of stress concentrators. Additional reinforcement with bends increases strength, but entails crushing of wood in the span .

3. A software calculation with taking into account the orthotropy of the material, shows that the value of the breaking load and the nature of the destruction does not depend on the nature of the reinforcement. Moreover, when calculating in accordance with the requirements of SP 64.13330.2011 "Wooden structures", the value of the breaking load is much lower, than when calculating with taking into account the wood orthotropy.

\section{Conclusions}

In the analysis of "high" and "low" glued reinforced wooden beams calculation results, there can be formulated the following main conclusions:

1. The nature of the "low" and "high" glued wooden beams destruction is different, and this must be taken into account when designing structures.

2. The calculation of structural elements, taking into account the orthotropy of the material, allows you to more accurately assess the stress distribution in the cross section, and to design them.

3. For "low" beams when calculated according to a linear and non-linear deformation scheme, the nature of reinforcement does not have a significant effect. When calculating beams taking into account orthotropy, a zone of uniform compression is formed, but at the same time, deflections increase.

6. "High" beams are characterized by the presence of a zone where reinforcement get the wood into the work. Which leads to an abrupt change in stress. When reinforcing beams along the diagram of compressive stresses, the redistribution of forces along the length occurs, which leads to a decrease in compressive stresses in the wood, and an increase in compressive stresses in the reinforcement.

\section{References}

1. Z. V. Belyaeva, R. I. Razborov, Acad. Bull. Uralniipr. 1(40), 74-78 (2019) https://doi.org/10.25628/UNIIP.2019.40.1.013

2. A. E. Pertseva, N. S. Hizhnyak, Transp. Constr. 5(3), (2018) https://doi.org/ 10.15862/02SATS318

3. V. S. Malykhina, V. G. Shukhov, Bull. Belgor. St. Tech. Univ. 6, 33-38 (2018) https://doi.org/ 10.12737/article_5b115a643c3876.11511924

4. H. Yang, D. Ju, W. Liu, W. Lu, Constr. Build. Mater. 109, 73-83 (2016) https://doi.org/10.1016/j.conbuildmat.2016.02.008

5. J. Soriano, B. Pellis, N. Mascia, Compos. Struct., 150, 200-207 (2016) https://doi.org/10.1016/j.compstruct.2016.05.016

6. M. I. Delova, V. G. Shukhov, Bull. Belgor. St. Tech. Univ. 4, $52-55$ (2017) https://doi.org/10.12737/article_58e61337b30965.84876518

7. I. P. Christovasilis, M. Brunetti, M. Follesa, M. Nocetti, D. Vassallo, Constr. Build. Mater. 122, 202-213 (2016) https://doi.org/10.1016/j.conbuildmat.2016.06.082

8. B. Gilbert, H. Bailleres, H. Zhang, R. McGavin, Constr. Build. Mater. 149, 763-777 (2017) https://doi.org/10.1016/j.conbuildmat.2017.05.153 
9. O.M. Ustarkhanov, G. G. Irzayev, Mod. Constr. Architect. 3 (11),16-20 (2018) https://doi.org/ 10.18454/mca.2018.11.2

10. G. Kandler, M. Lukacevic, C. Zechmeister, S. Wolff, J.Füssl, Constr. Build. Mater. 190, 573-592 (2018) https://doi.org/10.1016/j.conbuildmat.2018.09.129

11. B. C. Bal, Constr. Build. Mater. 112, 355-359 (2016) https://doi.org/10.1016/j.conbuildmat.2016.02.197

12. Z. Wang, H. Fu, M. Gong, J. Luo, Y. Hei Chui, Constr. Build. Mater. 151, 172-177 (2017) https://doi.org/10.1016/j.conbuildmat.2017.04.205

13. F. Gaspar, H. Cruz, A. Gomes, Constr. Build. Mater. 98, 447-455 (2015) https://doi.org/10.1016/j.conbuildmat.2015.08.011

14. T-T. Tran, V-D. Thi, M. Khelifa, M. Oudjene, Y. Rogaume, Constr. Build. Mater. 178, 462-472 (2018) https://doi.org/10.1016/j.conbuildmat.2018.05.080

15. S Berg, D Sanberg, M Ekevad, M Vaziri Wood Mater. Sci. Engin. 10(4), 335-343 (2015) https://doi.org/10.1080/17480272.2015.1027268

16. M. Lukacevic, J. Füssl, R. Lampert, Engin. Fract. Mech. 144, 158-175 (2015) https://doi.org/10.1016/j.engfracmech.2015.06.066 